AAOUJ

12,2

154

Received 7 November 2017 Revised 30 November 2017 Accepted 1 December 2017

\section{Persuading student involvement via peripheral services offered}

\author{
Hansani Chathurika Dassanayake \\ Department of Decision Sciences, Faculty of Management Studies and Commerce, \\ University of Sri Jayewardenepura, Nugegoda, Sri Lanka \\ Busige Nishantha \\ Department of Management and Organizational Studies, \\ Faculty of Management and Finance, University of Colombo, \\ Colombo, Sri Lanka, and \\ Asanka Senevirathne \\ Department of Management Studies, Faculty of Humanities and Social Sciences, \\ The Open University of Sri Lanka, Nawala, Sri Lanka
}

\begin{abstract}
Purpose - The purpose of this paper is to investigate the impact of peripheral services offered by distance education (DE) institutes on student involvement in $\mathrm{DE}$ and, examine whether this impact is mediated by student experience quality.

Design/methodology/approach - Quantitative research approach based on cross-sectional survey design was used where data were collected using a structured questionnaire. Sample consisted of 400 undergraduates of the Open University of Sri Lanka, drawn using simple random sampling technique. Collected data were analyzed using the structural equation model.

Findings - Data analysis revealed that there is a significant direct impact of peripheral services offered by $\mathrm{DE}$ institutes on student involvement in the Sri Lankan context. Furthermore, it is validated that this impact is mediated by student experience quality.

Research limitations/implications - Focus of the study is only on the impact of contextual elements rather than personal or demographic factors of students which can have an important impact on their experience quality as well as involvement.

Practical implications - Findings are useful in designing and redesigning service offering and policy development by DE institutes to make their services more appealing.

Originality/value - Even though previous studies have identified student dropout and lower academic excellence as issues in DE, how service offering can be used to overcome them via student involvement has not received considerable attention. Hence, the tested conceptual model developed on multiple theories is a novel contribution to the existing knowledge base.
\end{abstract}

Keywords Student involvement, Experience quality, Peripheral services

Paper type Research paper

\section{Introduction}

Since the ancient time, teacher-teaching and student-listening was the primary mode of education. They used to gather at a specific location at a specific time which was pre-determined (Sachar and Neumann, 2003). This arrangement immensely altered with the invention of educational delivery mechanisms powered by telecommunication and technological developments (Wang and Liu, 2003; Gunewardene and Lekamge, 2010). Prevailed temporal and geographical constraints for education were removed consequently

(C) Hansani Chathurika Dassanayake, Busige Nishantha and Asanka Senevirathne. Published in the Asian Association of Open Universities Journal. Published by Emerald Publishing Limited. This article is published under the Creative Commons Attribution (CC BY 4.0) licence. Anyone may reproduce, distribute, translate and create derivative works of this article (for both commercial and non-commercial purposes), subject to full attribution to the original publication and authors. The full terms of this licence may be seen at http://creativecommons.org/licences/by/4.0/legalcode 
by allowing students to make their learning decisions as what to learn, where to learn and how to learn (Sachar and Neumann, 2003). Physical face of academic establishments was also altered, and online classes, study material and libraries became more popular among community (Sachar and Neumann, 2003). This resulted in proliferation of study programs based on the distance education (DE) platform (Gunewardene and Lekamge, 2010). As the name stipulates, $\mathrm{DE}$ is a system of education or process of providing education or any instructional arrangement where teacher and student are geographically dispersed hence teaching behaviors are executed apart from learning behaviors (Moore et al., 2011; Simonson et al., 2008; Woolls et al., 2002; Rumble, 1989). Importantly, there is a gap between teacher and student where student is isolated and bear self-responsibility toward academic activities (Woolls et al., 2002). Students are provided with relevant study material and information to enable them to work by themselves. Therefore, they can study at their own time, at the place of their choice and without face-to-face contact with teachers and peers (Bates, 1995). On the other hand, from the earliest days, the rationale of $\mathrm{DE}$ has been to open opportunity for learners to pursue higher studies regardless of geographic, socio-economic or other constraints. Thus, a significant diversity in terms of age, family responsibilities, employment, aims and intentions among students is visible in the DE system comparing to the conventional education system (Rumble, 1989). These characteristics are unique to the DE system hence they demand for special course designing techniques, organizational as well as administrative arrangements (Sachar and Neumann, 2003; Moore et al., 2011; Woolls et al., 2002; Rumble, 1989).

Removing barriers to education has made DE as one of the most effective methods of pursuing education particularly for those who missed educational opportunities (Attri, 2012). However, reviewing scholarly work indicate that dropping out from study programs without completing them and lacking excellent academic performance by students are comparatively higher in the DE system comparing to conventional universities (Attri, 2012; Dadigamuwa and Senanayake, 2012; Willging and Johnson, 2004). This is backed by student-specific reasons as lacking responsibility toward own learning, inadequate understanding on the DE system and difficulty of managing numerous responsibilities at once while learning as well as system-specific features as depersonalized learning environment, poor interaction with peers and teachers and technological barriers (Attri, 2012; Dadigamuwa and Senanayake, 2012; Willging and Johnson, 2004; Farajollahi and Moenikia, 2010; Battalio, 2009).

Considering the Sri Lankan context, the Open University of Sri Lanka (OUSL) is the pioneer in DE which has an ever-increasing demand and popularity for its study programs since the inception (Wasala, 2010a, b). Other than the OUSL, there are multiple institutes attached to state and private universities offering distance-based study programs in different disciplines. Despite the demand, popularity and importance as an effective method of education, above-identified problems are visible in the Sri Lankan context at present. Informal interviews with the management of the OUSL conducted in April 2017 regarding one of the most demanded study programs, Bachelor of Management Studies (BMS) degree, revealed that graduation rate comparing to registration rate is significantly at a lower level, which is less than 10 percent. Furthermore, since students are provided with the opportunity of extending their degree, majority of them do not complete the degree during the stipulated four years' period. Specifically, among the graduates, small proportion has been able to secure a first class or second class upper division degree as many of undergraduates are looking for mere paper qualification.

Even though these problems have been observing over time, purpose of any DE provider would be enabling students to complete their study programs within the permitted time with superior performance and, encouraging and facilitating them to climb up in the academic ladder to become professionals with strong academic background in their
Persuading student involvement 
AAOUJ

12,2

respective fields. Allowing dropout from any study program restrains another students' potential of entering into the study program since all the institutions are competing for scarce resources. Particularly, DE is for those who missed their higher education (HE) opportunities due to some reason or the other, hence, restraining student opportunities to enroll into study programs can adversely affect their academic as well as professional development and finally well-being of the entire nation. Therefore, finding root causes and appropriate solutions are of paramount importance.

As emphasized by previous studies, suggestions to overcome prevailing problems in the DE context address aspects as teaching, teaching styles, teacher characteristics, assessment, facilities (Attri, 2012; Dadigamuwa and Senanayake, 2012; Farajollahi and Moenikia, 2010) as well as administrative, financial and advisory services and also opportunity for extra-curricular activities (Attri, 2012; Dadigamuwa and Senanayake, 2012; Lowes et al., 2007). These are primarily the services offered by DE institutes which include both main services, i.e. core services and support services, i.e. peripheral services. However, in the DE context, majority are part-time students who are employed and bear family and professional responsibilities. They expect hassle-free learning processes and environments such that peripheral services provided by institutes to augment the core services are comparatively more important as emphasized by previous studies in order to overcome the identified issues (Rumble, 1989).

Nevertheless, self-learning is one of the main concerns in the DE context where students have to play a significant role as they need to invest time and effort and get themselves involved in academic activities (Woolls et al., 2002). Thus, services offered by institutes alone cannot overcome above problems. As highlighted by theory of student involvement (Astin, 1984) and theory of student effort (Pace, 1984), academic involvement results in improved student learning and development whereas theory of student attrition says that the higher academic engagement with the institute reduces the likelihood of student dropout (Bean, 1980). Furthermore, empirical studies have proved a significant relationship between student involvement and their performance as well as lower dropout rates (Mwenje and Kasowe, 2013; Astin, 1984; Fischer, 2007; House, 2000). Therefore, in order to overcome the prevailing identified problem in the $\mathrm{DE}$ context making the student involved in academic matters is essential. Accordingly, student involvement can be identified as the mediator that links the input and output of the learning process where input is the services offered by DE institutes whereas output is the student success and retention (Astin, 1984). Thus, this paper attempts to find out the impact of peripheral services offered by $\mathrm{DE}$ institutes on student involvement in DE in Sri Lanka. On the other hand, DE is a service and every service encounter is accompanied by experiences where perception of the experience, i.e. experience quality, determines the behavior (Robbins and Judge, 2013). Therefore, this paper further investigates whether student experience quality mediates the above impact of peripheral services on student involvement in DE in Sri Lanka. Accordingly, the two main research questions of this paper are as follows:

$R Q 1$. Do the peripheral services offered by DE institutes affect student involvement in DE in Sri Lanka?

$R Q 2$. Does student experience quality mediate the impact of peripheral services offered by DE institutes on student involvement in DE in Sri Lanka?

\section{Literature review}

\subsection{Peripheral services}

Human needs and wants are satisfied through products offered by organizations. Even though products are traditionally categorized as goods or services, boundaries 
between them are blurring nowadays (Perera, 2009). Products are offered as a bundle and, depending on the relative proportion, they are categorized as either goods or services (Perera, 2009). Accordingly, HE is categorized as a service; specifically, it is a professional service which caters the need of learning and acquiring knowledge, expertise and skills. It offers opportunities as the product to its customers, i.e. students, with the help of tangible and intangible elements as infrastructure and faculty expertise, respectively (Raj et al., 2013; DeShields et al., 2005).

$\mathrm{HE}$ service is provided by people for people, directed at student mind via intangible actions, hence, it is a mental stimulus processing service which does not result in ownership of any physical item and benefits are therefore purely intangible. These benefits are unique to each student thus education service is heterogeneous even though all the students are offered with the same service (Lovelock and Wirtz, 2013; Canterbury, 1999).

Even though HE service is offered as a single package to students, who are the primary customers, it consists of number of tangible and intangible elements together which create a value to students. A service package is a combination of core and peripheral services (Lovelock and Wirtz, 2013; Roth and Menor, 2003). Core services are the basic problem-solving benefits students seek or needs trying to fulfill and thereby the reason for service transaction (Lovelock and Wirtz, 2013; Canterbury, 1999; Gronroos, 2008). Peripheral services are supplementary to core services which provide additional benefits, enhance service value and contribute to differentiate the service from substitutes (Lovelock and Wirtz, 2013; Canterbury, 1999; Gronroos, 2008). As presented in the service flower model (Lovelock and Wirtz, 2013), peripheral services can be further classified into facilitating services and enhancing services. Facilitating services facilitate the use of core services whereas enhancing services enhance the value and appeal of core services (Lovelock and Wirtz, 2013). Accordingly, in the DE context, enquiry; admission and pre-study advisory services; career guidance and counseling services; record keeping; provision of timely and relevant information; information management; and other administrative support can be identified as facilitating services. Similarly, enhancing services include multiple payment methods and related applications; financial aids; online registration and related online support; differentiated services for students with special needs of one sort or another and; extra-curricular and recreational facilities (Foreman and Retallick, 2013; Jung, 2012; Douglas et al., 2006; Kretovics, 2003).

\subsection{Student involvement}

Theory of student involvement defines student involvement as the amount of physical and psychological energy that a student devotes to college experience (Astin, 1984). It is the ability of an individual to take charge of own learning by setting goals, identifying gaps in knowledge and addressing them through a self-monitoring process (Bates, 1995). An academically involved student may participate in classroom discussions or study by him or herself, hence, student involvement can happen in both inside or outside the classroom (Sidelinger and Booth-Butterfiled, 2010). Thus, involvement can be observed and measured qualitatively or quantitatively with respect to each student (Foreman and Retallick, 2013). Accordingly, student involvement is a behavioral phenomenon (Astin, 1984; Butzow and Williams, 1977) and connected with the individual student. When a student is academically involved, he or she utilizes considerable amount of available time on reading course material; other relevant books; use library; logging to learning management system frequently; make separate notes; utilize their learning into day-to-day activities specifically in their work settings; attend lectures; and actively participate in classroom discussions. Also, they interact with lecturers to discuss subject matters, academic plans and tend to look for feedback on their performance as well as other academic and career-related progression.
Persuading student involvement 
AAOUJ 12,2

They also take part in collaborative learning with peers, spend time in studying and tutoring as well as sharing experience on study programs and future plans with peers (Astin, 1984; Sidelinger and Booth-Butterfiled, 2010; Pass, 2013; Jaafar et al., 2012).

\subsection{Student experience quality}

Services are always accompanied by experience since they result in experiential effects

(Lemon and Verhoef, 2016). Experience is the intangible takeaways from service encounters which originate from a set of interaction between the customer and a product, a company or part of its organization over several touch points in the service journey (Walter et al., 2010). In $\mathrm{HE}$, students bring certain characteristics with them and interact with services provided by institute resulting in a learning experience. As per student life cycle, student experience starts when a student decides to study at university and evolves through the phases as application, registration, teaching, learning and assessment, graduation and post-qualification experience. It is not limited to classroom learning or academic matters but covers whole experience they are going through including out of class non-academic aspects as student support and administrative activities as well as social aspects as forming new friendships, advising and mentoring (Arambewela and Maringe, 2012; Ng and Forbes, 2008). The most developed aspects of customer experience measurements concern customer perceptions of parts of the service journey or of the overall customer experience based on their affective analysis of service which is known as customer experience quality (Lemon and Verhoef, 2016; Jutter et al., 2013). From student point of view, student experience quality is the students' perceptions of direct and indirect inputs they receive from their college which indicate student's own view toward the variety of aspects such as curricula, program delivery, quality of instruction and learning support. If their expectations on these elements are met, they tend to rate it as a quality experience, and if not, other way around (Horvat et al., 2012; Baird and Gordon, 2009; Neumann and Neumann, 1993).

\subsection{Impact of peripheral services on student involvement}

There are empirical studies that have identified consequences of student involvement rather than its antecedents particularly in the DE context (Astin, 1984; Pace, 1984). Specifically, how student involvement is affected by services offered by institutes has not gained enough empirical attention earlier, hence this paper attempts to bridge the prevailing knowledge gap (Astin, 1984). Theory of student involvement provides the theoretical foundation for this relationship. As one of the postulates of the theory emphasizes, if educational policies and practices of an $\mathrm{HE}$ institute are effective, it will result in increased involvement in academic activities by its students (Astin, 1984). These policies and practices provide the ground rules for functionality of the institute such that what it offers to students and how it is offered are part of these policies and practices (Bell and Stevenson, 2006). Therefore, it can identify that core and peripheral services offered are included in and also influenced by these educational policies and practices of the institute. Since there are limited amount of previous studies that have explicitly identified the impact of these peripheral services on student involvement (Dassanayake and Nishantha, 2017), by analyzing scattered findings, it can identify that peripheral services result in effective student involvement. For instance, facilitating services as administrative support and provision of timely information address alienation feature unique to DE whereas enhancing services as multiple and flexible payment methods aligning with modern technological innovations makes it convenient for students to execute their studies without constraints. Since majority of learners in the DE system are working adults with family responsibilities, financial support in terms of scholarships or payment in installments can assist students in continuation of their studies. These peripheral services provide a hassle-free supportive learning environments and conditions for students where they feel committed and comfortable with the institution 
resulting in higher integration with the academic activities (Dassanayake and Nishantha, 2017; Foubert and Grainger, 2006; Huang and Chang, 2004; Foreman and Retallick, 2013; Kretovics, 2003). Accordingly, based on theoretical and empirical grounds, following hypothesis is proposed in this paper:

H1. Peripheral services offered by DE institutes positively influence on student involvement in DE in Sri Lanka.

\subsection{Mediating role of student experience quality}

Mehrabian and Russel model which is based on stimuli-organism-response framework highlights that individual's feelings and emotions evoked by environmental stimuli ultimately determine their behavior (Billings, 1990; Robbins and Judge, 2013). Environmental stimuli are what people receive with their senses and after interpreting them on their own view, an emotional state expands into either one of pleasure or of arousal. Next the person responds to the emotional state through a behavior which can be either approach or avoidance related. An approach- or positive-related behavior indicates that the person possess a better feeling and vice versa. Hence, it is apparent that emotions indicate a person's perception on stimuli and it will result in his or her behavior (Robbins and Judge, 2013). Accordingly, in the HE context, peripheral services can be treated as stimuli received by students, more specifically contextual stimuli, and their involvement is the behavioral response to those stimuli which is mediated by their perception on learning experience, i.e. experience quality, gained from those services.

Students in the DE platform carry a diverse profile and their expectations on services offered are not merely limited to curriculum, pedagogy or assessment rather essentially related to how the DE institute responds to their needs and commitments (Entwistle and Tait, 1990). Student perception on experience can be therefore influenced by additional and value-added service provided (Arambewela and Maringe, 2012). Comprehensive orientation programs, provision of information, guidelines and instructions facilitate smooth functioning of student activities. Financial, social or psychological support and guidance to students remove external barriers to academic performance. Use of latest information and communication technology is seen as essential in creating stimulating learning environments characterized by features as blended learning, remote access to live lectures, access to digital libraries and networking of students, academic staff, research assistants and learning resources. Opportunities for extra-curricular activities also make student academic life more interesting and entertaining. Therefore, these well-designed peripheral services create emotional feelings outside the main functional solution which subsequently result in better perception regarding their student experience (Arambewela and Maringe, 2012; Fraser et al., 1987; Jung, 2012; Thapliyal, 2014).

On the other hand, Entwistle and Tait (1990) specifically identified a direct relationship between student perception and actions. Positive perception on their learning experience influences desirable study behaviors which results in increased student involvement. When meaningful learning experiences are missing, students often become disengaged and dissatisfied because they see no relevance in what they are learning. Accordingly, students with few chances to participate in meaningful learning experiences are denied the opportunity to integrate and apply the knowledge they have obtained in their classes. Therefore, contemporary research in student learning has also suggested a relationship between learning experience and study behavior. Better the student experience, i.e. when student perceive their learning experience as of high quality, it will therefore eventually increase their involvement in academic activities (Sidelinger and Booth-Butterfiled, 2010; Entwistle and Tait, 1990; Sadlo and Richardson, 2003; Lizzio et al., 2002). Therefore, based on these theoretical and empirical foundations, following hypotheses are proposed to test

Persuading student involvement 
AAOUJ

12,2

\section{0}

Figure 1.

Conceptual framework the mediating effect of student experience quality on the relationship between peripheral services and student involvement:

H2. Peripheral services offered by $\mathrm{DE}$ institutes positively influence on student experience quality in DE in Sri Lanka.

H3. Student experience quality positively influence on student involvement in DE in Sri Lanka.

H4. Student experience quality mediates the relationship between peripheral services offered by DE institutes and student involvement in DE in Sri Lanka.

Based on the above-identified relationships, therefore, the following conceptual framework is proposed by this paper which is subject to empirical validation through a rigorous data collection and analysis (Figure 1).

\section{Methodology}

This study establishes relationships between study variables rather than in-depth exploration hence can be categorized as an explanatory study. Since it looks into gathering data on student opinion, data were collected at a specific time from the sample such that this is a cross-sectional study considering the time horizon and followed the deductive approach as hypotheses were developed based on established theories. Study sample consisted of 400 undergraduates of the BMS degree program, who are the sampling unit, drawn using the simple random sampling technique (Saunders et al., 2011; Sekaran and Bougie, 2014). Structured questionnaire developed based on a rigorous literature review was used as the primary data collecting instrument. Questionnaire consisted of two sections where section 1 measured student opinion regarding the study constructs and section 2 collected data on demographic factors of the respondent. Study variables were measured at five-point Likert scale ranging from $1=$ strongly disagree to $5=$ strongly agree by modifying and adapting to existing measures. Table I presents the operationalization of each construct (refer Table AI for complete operationalization information).

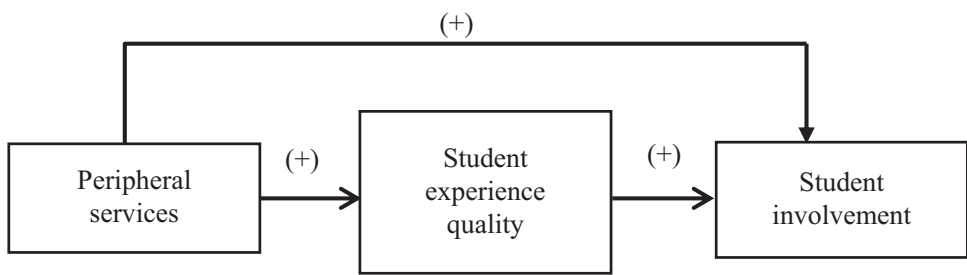

\begin{tabular}{|c|c|c|c|}
\hline Construct & Definition & Dimension & $\begin{array}{l}\text { Literature } \\
\text { source }\end{array}$ \\
\hline $\begin{array}{l}\text { Peripheral } \\
\text { services (PS) }\end{array}$ & $\begin{array}{l}\text { Supplementary to core services offered by } \mathrm{DE} \\
\text { institutes which provide additional benefits } \\
\text { and enhance service value to students }\end{array}$ & $\begin{array}{l}\text { Facilitating services (FS), } \\
\text { enhancing services (EnS) }\end{array}$ & Jung (2012) \\
\hline $\begin{array}{l}\text { Student } \\
\text { experience } \\
\text { quality (SExQ) }\end{array}$ & $\begin{array}{l}\text { Perceived superiority of holistic service } \\
\text { encounter or the experience of the student }\end{array}$ & & $\begin{array}{l}\text { Bujisic } \\
(2014)\end{array}$ \\
\hline $\begin{array}{l}\text { Student } \\
\text { involvement } \\
\text { (SI) }\end{array}$ & $\begin{array}{l}\text { Amount of physical and psychological effort } \\
\text { devoted by a student for academic activities }\end{array}$ & $\begin{array}{l}\text { Active participation (AP), } \\
\text { self-learning (SL), student } \\
\text { faculty interaction (Int), learning } \\
\text { with peers (LP) }\end{array}$ & $\begin{array}{l}\text { Indiana } \\
\text { University } \\
(2017)\end{array}$ \\
\hline
\end{tabular}

Table I.

Operationalization of study variables 
In order to overcome common method variance (CMV), at the questionnaire designing stage, procedural remedies as ensuring respondent's anonymity in the attached cover letter and providing proper instructions to psychologically separate the measures were made (Podsakoff et al., 2003). Pilot study was undertaken to identify the time taken to complete the questionnaire, verbal correctness, confusions and unclear areas. Based on the feedback, required modifications were done. Using the online method, 700 questionnaires were distributed among sampling units in June 2017 and reminder notes were sent to encourage the response.

After collecting and removing incomplete questionnaires, coded questionnaires were fed to SPSS 20.0 to treat outliers and missing values. For the preliminary analysis, 386 questionnaires were used. Multivariate assumptions of normality, linearity, multicolinearity and homoscedasticity were ensured as they are essential to conduct the structural equation model. Since available measures were modified to suit to the study context, exploratory factor analysis was performed with respect to each construct to test the factor structure using principle component analysis as extraction method and Varimax with Kaiser normalization as rotation method and thereby confirmed the unidimensionality of measures. Furthermore, reliability of measures was tested by Cronbach's $\alpha$ value calculated for each dimension and construct. Since all the calculated values were greater than 0.6, high internal consistency was validated. The purified data were next fed to AMOS 21.0 version to develop the measurement model which examines the relationship between latent variables and their measures and, structural model which examines the relationship between latent variables. Measurement model was tested with confirmatory factor analysis. Model fit was improved using modification indices and removing factor loadings less than 0.45. Resulted goodness-of-fit (GOF) indices were above the cut-off values indicating that model provides a reasonably good fit. Convergent validity of measures was tested using composite reliability (CR) and average variance extracted (AVE). Accordingly, CR and AVE values of all dimensions and constructs were greater than 0.60 and 0.50 , respectively. Therefore, based on CR and AVE, convergent validity of measures was established. Similarly, discriminant validity could also establish as AVE values for all the dimensions and constructs were greater than the corresponding squared correlation coefficients. Finally, Harman's single factor was calculated to test whether data are free of CMV. Result revealed that the presence of six distinct factors with eigenvalue greater than 1.00 together accounted for 61.51 percent of the total variance; the first factor did not account for a majority of the variance (22.29 percent). Thus, no general factor was apparent. Accordingly, these results did suggest that CMV is not of great concern and thus is unlikely to confound the interpretations of results. After testing the multivariate assumptions, ensuring unidimensionality, reliability and validity of measures, finally structural model was developed to test the study hypotheses (Saunders et al., 2011; Sekaran and Bougie, 2014; Podsakoff et al., 2003; Hair et al., 2009).

\section{Data analysis}

\subsection{Sample profile}

The study sample consists of undergraduates of the BMS degree offered by the OUSL. They are attached to Colombo, Kandy and Matara regional centers where students attached to Colombo regional center represent the highest participation in survey. Respondents are studying at all the levels in the degree program and 45 percent of them are from level 6 , such that they are possessed with considerable knowledge on services offered by the university. Aligning to typical characteristics of DE, 67 percent of students are employed and most importantly 67 percent of the sample bears family commitments in terms of financial contribution to their families. However, contrary to previous findings, sample consists of only 33 percent of married students and majority of respondents are females accounting 60 percent of the sample.

\section{Persuading student involvement}


AAOUJ

12,2

162

\subsection{Structural model and hypotheses testing}

Upon theoretical and empirical basis, this paper proposed four hypotheses of which one is related to the direct impact of peripheral services on student involvement whereas others test the indirect impact proposing student experience quality as the mediator. In order to test these hypotheses, structural model (Figure 2) was developed upon the validated measurement model and bootstrapping method was used to test the mediator effect.

The corresponding GOF indices of the model are presented in Table II.

Accordingly, CIMIN/DF is less than 3, RMSEA is well below 0.08 and PRATIO is 0.9 . GFI and AGFI values are closer to 0.9 and IFI, TLI and CFI have reached 0.9. Thus, it could conclude that GOF of the structural model was at an acceptable level and thereby can be used to test the four hypotheses of the study (Hair et al., 2009). Table III summarizes the results of the hypotheses testing.

Results indicate that all the four hypotheses are significant at the 95 percent confidence level. Both the direct and indirect paths are therefore significant in the model. Thus, peripheral services have a direct positive impact on student involvement and indirect positive impact on student involvement via student experience quality. Therefore, student experience quality can be identified as a mediator on the impact of peripheral services

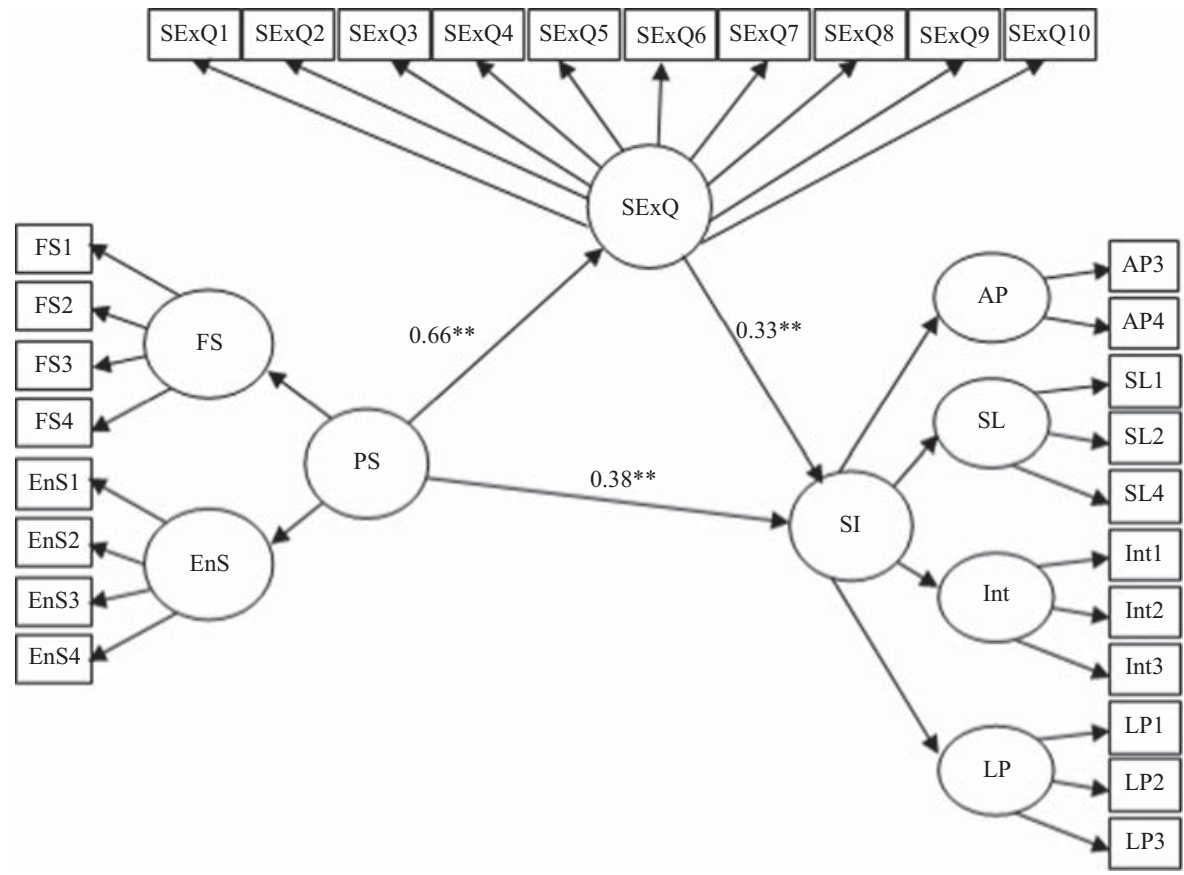

Figure 2.

Structural model

Note: ${ }^{* *} p<0.05$

Table II.

GOF indices of the structural model

\begin{tabular}{lccccccc}
\hline $\begin{array}{l}\text { Absolute } \\
\text { CIMIN/DF }\end{array}$ & GFI & AGFI & RMSEA & IFI & $\begin{array}{c}\text { Incremental } \\
\text { TLI }\end{array}$ & CFI & $\begin{array}{c}\text { Parsimony } \\
\text { PRATIO }\end{array}$ \\
\hline 2.14 & 0.87 & 0.84 & 0.06 & 0.92 & 0.90 & 0.91 & 0.90 \\
\hline
\end{tabular}




\section{Hypotheses}

Result of

$H 1$ Peripheral services offered by DE institutes positively influence on student $0.38 \quad 0.00 * *$ Supported involvement in DE in Sri Lanka

H2 Peripheral services offered by DE institutes positively influence on student $0.68 \quad 0.00 * *$ Supported experience quality in DE in Sri Lanka

$H 3$ Student experience quality positively influence on student involvement in $0.330 .00 * *$ Supported DE in Sri Lanka

H4 Student experience quality mediates the relationship between peripheral services offered by DE institutes and student involvement in DE in Sri Lanka

Note: ${ }^{* *} p<0.05$
Persuading student involvement

$0.220 .00 * *$ Supported

Table III.

Results of the hypotheses testing

offered by DE institutes on student involvement. On the other hand, the path coefficient, $\beta$, is lower in the indirect path than the direct path. This indicates that student experience quality partially mediates the impact of peripheral services on student involvement.

\section{Discussion and conclusion}

\subsection{Discussion}

The proposed direct impact of peripheral services on student involvement on the basis of theory of student involvement as well as empirical findings was substantiated in the Sri Lankan context. This aligns to previous findings as they highlight that effective peripheral services encourage students to pay more attention on their academic activities (Dassanayake and Nishantha, 2017; Astin, 1984; Foubert and Grainger, 2006; Huang and Chang, 2004). Properly designed orientation programs which enable students to have an overall understanding on the DE system and means of succeeding; administrative support as dissemination of timely information, well-organized documentation processes, quick response and helpful non-academic staff members; financial support specially payment in installments, scholarships and multiple payment methods; counseling services and psychological support as well as career guidance since majority are working students who need to balance their family life and work life while learning will create a hassle-free learning opportunities and environments to students. Furthermore, opportunities for extra-curricular activities as participation in student associations and sports make the student life more interesting. When these peripheral services are effectively designed and organized, it eliminates the need of students to pay extra attention on non-academic matters, make the learning process convenient and interesting without extra burden which bridges the detached student closer to the institute. Due to hassle-free convenient and interesting learning environment, students tend to pay more attention on their studies and perform well.

The proposed mediating effect of student experience quality on the impact of peripheral services on student involvement which is based on the Mehrabian and Russell model was validated in the Sri Lankan context. Even though this impact has not been previously explicitly tested in the DE context, considering the scattered findings on elements of peripheral services provided by DE institutes, it can identify that better services result in better evaluation by students regarding their experience. Thus, aligning with previous findings, it can be concluded that in order to create an actual value of student experience, proper construction of not only main services but also peripheral services offered by the education institute is required ( $\mathrm{Ng}$ and Forbes, 2008). Similarly, these findings are consistent to previous findings conducted in other service contexts as in restaurants, hotels and transportation (Kozak and Gurel, 2015; Fatma, 2014; Yuksel and Yuksel, 2016; Tombs and McColl-Kennedy, 2003). In the broadest sense, they have identified that service quality, 
AAOUJ

12,2

164

product quality, pricing and price fairness, service environment, processes, service convenience and employees are the key drivers of customer experience quality. Accordingly, provision of information, feedback procedures, responsiveness and quick service provision, use of multiple channels of customer interaction, use of latest technologies, convenient payment processes and value-added services as playing music in service location are identified as drivers of customer experience quality which can be categorized as peripheral services. Such that, based on findings of the previous studies, it can also affirm that peripheral services are linked to customer experience quality.

On the other hand, due to unique characteristics of students in the DE platform as employment status and family commitments, they prefer to have a hassle-free learning environment such that provision of these peripheral services makes the service they receive more appealing. This can be mainly since people are more attractive nowadays toward the additional benefits they receive other than the basic service. Even though they are not essential to fulfill the basic requirement, people expect service provider to make the service they receive more unique, memorable and convenient by accompany them with these additional services. If they are provided with such service, they tend to evaluate their experience as superior. Reasons for these changes can be attributable to shift in socio-demographic factors particularly improvements in life style which is influenced mainly by the technological developments.

When considering the impact of student experience quality on student involvement, study findings are consistent with previous studies. Specifically, Klaus and Maklan (2012) and Entwistle and Tait (1990) concluded a direct relationship between student perception and actions while Ning and Downing (2011) concluded that student perception of learning experience directly affect their study behaviors. Since student involvement is a behavioral phenomenon, therefore, study findings convey a consistence with existing knowledge. Similarly, in other service industries also, it has proven that customer perception drives their behavior and behavioral intentions as repeat purchase, word of mouth communication as well as loyalty and satisfaction (Kim and Choi, 2016; Lemon and Verhoef, 2016).

Even though mediating impact of student experience quality has not been explicitly tested in previous studies, based on available knowledge in DE as well as in other service sectors, therefore, it is apparent that study findings are consistent with existing knowledge. Accordingly, findings of this study along with previous findings fulfill the requirements to consider a variable as a mediator. Since the proposed novel mediating impact was substantiated by the study findings, this study contributes new knowledge and extends the existing knowledge base specific to DE in the Sri Lankan context.

\subsection{Conclusion}

Even though DE has been identified as one of the most effective means of education, recent trends indicate that student dropout and comparatively lower academic excellence are critical issues in the system. Therefore, this paper primarily investigated the role of peripheral services offered by DE institutes in enhancing student involvement in order to overcome those identified issues. Study findings proved that peripheral services directly and indirectly influence on student involvement. Accordingly, it is apparent that if DE institutes offer better peripheral services, it will improve student involvement and due to partial mediating effect of student experience quality, such services let students to perceive their learning experience as of high quality and affect their behavior in terms of enhanced utilization of time and effort on academic matters. Therefore, careful design of peripheral services which augment the core offering of DE institutes by considering educational philosophies, organizational capabilities along with the voice of students is of paramount importance in overcoming the prevailing issues to make DE more effective and fruitful. 


\section{Implications and further studies \\ 6.1 Implications}

Findings of this study are enriched with theoretical as well as managerial implications. The validated theoretical framework of the study was developed by combining two theories in order to address the prevailing issues in the DE context. Particularly, much of the previous studies have focused on consequences of student involvement rather than its drivers. Also the established mediating effect of student experience quality has not been previously tested in the study context. Therefore, while addressing these prevailed gaps in the existing knowledge base, the validated theoretical model of the study can be identified as a novel contribution which is unique to the DE context. On the other hand, even though previous studies have emphasized on dropout and lower academic performance as problems in the DE context, limited studies have explicitly addressed how contextual elements as services offered by institutes along with student contribution can overcome the identified problems. Therefore, the findings bridge this empirical gap in the knowledge base.

Most importantly, the findings are significant in terms of managerial or practical means. They provide valuable input to the institutes specifically in service designing and redesigning. Since peripheral services can make positive impact upon utilization of time and effort on academic activities by students, institutes need to ensure that they provide all the relevant, comprehensive and up-to-date services in addition to their core services as teaching, learning and evaluation. Particularly, due to existence of partial mediating effect, it is essential to ensure that services provided are perceived by students as of high quality. Even though quality is a subjective phenomenon, designing services considering industrial requirements, student demand and their priorities, as well as principles of service designing along with educational theories and philosophies will enable institutes to deliver a quality service that encourage students toward academic involvement. Thus, the study findings provide significant inputs for educational policy developments and thereby making the service offered by these institutes more appealing. Such managerial decisions will enable to overcome identified critical and inherent issues in the system.

However, as a whole, findings of the study have societal impact as educated citizens are a real asset to any nation. Educating citizens therefore influence on their well-being and thereby the development of the entire nation. It is a known fact that DE is an effective mean of offering academic programs for those who missed higher studies or those who have inner quest for higher studies. Therefore, it is essential to identify and provide solutions to the problems of the DE system to make sure that intended benefits of it are reaped. Findings of this study therefore provide important input to decision makers in designing study programs in a way that enhances student involvement in academic activities. On one aspect, this enables students to attain academic qualifications while enhancing their knowledge and enabling them to make better contribution to professional as well as personal life. On the other hand, DE institutes would be able to make better decisions by allocating their scare resources in a productive manner for the betterment of the nation. In addition, higher student performance and reported lower dropout rates resulting from better services offered by $\mathrm{DE}$ institutes will positively affect the goodwill of the institute and create market recognition as well as confidence among potential students. Thus, findings emphasize on need of reconsidering about DE system as a whole in order to make it more beneficial to the wider society and thereby making the nation literate.

\subsection{Further studies}

Despite the study implications, there are number of limitations that can be addressed in future studies. The sample of the study consisted of undergraduates of the BMS degree offered by the OUSL. Since there are plenty of other institutes that offer distance-based study programs in different disciplines, future studies can select a sample to incorporate a
Persuading student involvement 
AAOUJ

12,2

166

wider diversity in the sample which can gain more insight into the study phenomenon. On the other hand, there is high diversity among students in the DE system due to removal of barriers to education. Even though all are offered with the same services, their perception may be influenced by individual characteristics as their employment status, age or own study intentions and desires. Therefore, the impact of peripheral services offered by institutes on student experience quality can be affected by these student characteristics such that in future studies they can be incorporated as moderating variables to the validated theoretical framework. Similarly, this study gathered data from students which present their opinion on study variables. Future studies can gather service provider opinion, particularly on services they offer and thereby can perform a gap analysis in order to identify the unmet desires of student which will be helpful in service designing process.

\section{References}

Arambewela, R. and Maringe, F. (2012), "Mind the gap: staff and postgraduate perceptions of student experience in higher education", Higher Education Review, Vol. 44 No. 2, pp. 63-84.

Astin, A.W. (1984), "Student involvement: a developmental theory for higher education", Journal of College Student Personnel, Vol. 25, pp. 297-308.

Attri, A.J. (2012), "Distance education: problems and solutions", International Journal of Behavioral Social and Movement Sciences, Vol. 1 No. 4, pp. 42-58.

Baird, J. and Gordon, G. (2009), "Beyond the rhetoric: a framework for evaluating improvements to the student experience", Tertiary Education and Management, Vol. 15 No. 3, pp. 193-207.

Bates, A. (1995), Technology, Open Learning and Distance Education, Routledge, London.

Battalio, J. (2009), "Success in distance education: do learning styles and multiple formats matter?", The American Journal of Distance Education, Vol. 23 No. 2, pp. 71-87.

Bean, J.P. (1980), "Dropouts and turnover: the synthesis and test of a causal model of student attrition", Research in Higher Education, Vol. 12 No. 2, pp. 155-187.

Bell, L. and Stevenson, H. (2006), Education Policy: Process, Themes and Impact, Routledge, London.

Billings, W.L. (1990), "Effects of store atmosphere on shopping behavior", available at: http:// digitalcommons.iwu.edu/cgi/viewcontent.cgi?article=1014\&context=busadmin_honproj (accessed April 2, 2017).

Bujisic, M. (2014), “Antecedents and consequences of customer experience in beverage establishments", available at: http://etd.fcla.edu/CF/CFE0005309/Dissertation_Milos_Bujisic_June_30.pdf (accessed March 29, 2017).

Butzow, J.W. and Williams, C.M. (1977), "Towards a definition of involvement: translating a humanistic concept into a behavioral model”, Science Education, Vol. 61 No. 4, pp. 479-490.

Canterbury, R.M. (1999), "Higher education marketing: a challenge", The Journal of College Admission, Vol. 16 No. 5, pp. 22-30.

Dadigamuwa, P.R. and Senanayake, S. (2012), "Motivating factors that affect enrolment and student performance in an ODL engineering programme", The International Review of Research in Open and Distance Learning, Vol. 13 No. 1, pp. 244-256.

Dassanayake, H.C. and Nishantha, B. (2017), "Enhancing student involvement through service package offered: case of distance education in Sri Lanka”, The 12th International Research Conference on Management and Finance, University of Colombo, Colombo, pp. 177-194.

DeShields, O.W., Kara, A. and Kaynak, E. (2005), "Determinants of business student satisfaction and retention in higher education: applying Herzberg's two-factor theory", International Journal of Educational Management, Vol. 19 No. 2, pp. 128-139.

Douglas, J., Douglas, A. and Barnes, B. (2006), "Measuring student satisfaction at a UK university", Quality Assurance in Education, Vol. 14 No. 3, pp. 251-267. 
Entwistle, N. and Tait, H. (1990), "Approaches to learning, evaluations of teaching, and preferences for contrasting academic environments", Higher Education, Vol. 19, pp. 169-194.

Farajollahi, M. and Moenikia, M. (2010), "The study of relation between students support services and distance students' academic achievement”, Procedia - Social and Behavioral Sciences, Vol. 2 No. 2, pp. 4451-4456.

Fatma, S. (2014), "Antecedents and consequences of customer experience management: a literature review and research agenda", International Journal of Business and Commerce, Vol. 3 No. 6, pp. 32-49.

Fischer, M.J. (2007), "Settling into campus life: differences by race/ethnicity in college involvement and outcomes", Journal of Higher Education, Vol. 78 No. 2, pp. 125-161.

Foreman, E.A. and Retallick, M.S. (2013), "Using involvement theory to examine the relationship between undergraduate participation in extra-curricular activities and leadership development", Journal of Leadership Education, Vol. 12 No. 2, pp. 56-73.

Foubert, J.D. and Grainger, L. (2006), "Effects of membership in clubs and organizations on the psychosocial development of first year and senior college students", Journal of Student Affairs Research and Practice, Vol. 43 No. 1, pp. 166-182.

Fraser, B.J., Walberge, H.J., Welch, W.W. and Hatties, J.A. (1987), "Synthesis of educational productivity research", International Journal of Educational Research, Vol. 11 No. 2, pp. 147-252.

Gronroos, C. (2008), "Service logic revisited: who creates value? And who co-creates?", European Business Review, Vol. 20 No. 4, pp. 298-314.

Gunewardene, G.I.C. and Lekamge, G.D. (2010), "Open and distance learning transformed: possible adaptations to suit special contexts", OUSL Journal, Vol. 6, pp. 22-43.

Hair, J., Black, W.C., Babin, B.J. and Anderson, R.E. (2009), Multivariate Data Analysis, Prentice Hall, Chollerstrasse.

Horvat, A., Krsmanovic, M. and Djuric, M. (2012), "Differences in students' satisfaction with distance learning studies", International Journal of Social, Behavioral, Educational, Economic, Business and Industrial Engineering, Vol. 6 No. 6, pp. 1412-1415.

House, J. (2000), "The effects of student involvement on the development of academic self-concept", Journal of Social Psychology, Vol. 140 No. 2, pp. 261-263.

Huang, Y. and Chang, S. (2004), "Academic and co-curricular involvement: their relationship and the best combinations for student growth", Journal of College Student Development, Vol. 45 No. 4 , pp. 391-406.

Indiana University (2017), "NSSE - National Survey of Student Engagement", available at: http://nsse. indiana.edu/html/engagement_indicators.cfm (accessed April 2, 2017).

Jaafar, F.M.D., Hashim, R.A. and Ariffin, T.F.T. (2012), "Malaysian university student learning involvement scale (MUSLIS): validation of a student engagement scale", Malaysian Journal of Learning and Instruction, Vol. 9, pp. 15-30.

Jung, I. (2012), "Asian learners perception of quality in distance education and gender differences", The International Review of Research in Open and Distance Learning, Vol. 13 No. 2, pp. 1-25.

Jutter, U., Schaffner, D., Windler, K. and Maklan, S. (2013), “Customer service experience: developing and applying a sequential incident laddering technique", European Journal of Marketing, Vol. o. 47 No. 5, pp. 738-768.

Kim, H.S. and Choi, B. (2016), "The effects of three customer-to-customer interaction quality types on customer experience quality and citizenship behavior in mass service settings", Journal of Services Marketing, Vol. 30 No. 4, pp. 384-397.

Klaus, P. and Maklan, S. (2012), "EXQ: a multiple-item scale for assessing service experience", Journal of Service Management, Vol. 23 No. 1, pp. 5-33.

Kozak, M.A. and Gurel, D.A. (2015), "Service design in hotels: a conceptual review", An International Interdisciplinary Journal, Vol. 63 No. 2, pp. 225-240.

\section{Persuading student involvement}


AAOUJ

12,2

168

Kretovics, M. (2003), "The role of student affairs in distance education: cyber-services or virtual communities", Online Journal of Distance Learning Administration, Vol. 6 No. 3, pp. 47-61, available at: www.westga.edu/ distance/ojdla/fall63/kretovics63.html (accessed March 12, 2017).

Lemon, K.N. and Verhoef, P.C. (2016), "Understanding customer experience throughout customer journey”, Journal of Marketing, Vol. 80 No. 6, pp. 69-96, available at: www.researchgate.net/ publication/304029900 (accessed March 23, 2017).

Lizzio, A., Wilson, K. and Simons, R. (2002), "University students' perception of the learning environment and academic outcomes: implications for theory and practice", Studies in Higher Education, Vol. 27 No. 1, pp. 27-52.

Lovelock, C. and Wirtz, J. (2013), Services Marketing: People, Technology \& Strategy, Prentice-Hall, Upper Saddle River, NJ.

Lowes, S., Lin, P. and Wang, Y. (2007), "Studying the effectiveness of the discussion forum in online professional development courses", Journal of Interactive Online Learning, Vol. 6 No. 3, pp. 181-210.

Moore, J.L., Dickson-Deane, C. and Galyen, K. (2011), "E-learning, online learning and distance learning environments: are they the same?", Internet and Higher Education, Vol. 14 No. 2, pp. 129-135.

Mwenje, S. and Kasowe, R. (2013), "Student involvement in enhancing student retention, persistence and success in open and distance learning at Zimbabwe open university", African Educational Research Journal, Vol. 1 No. 1, pp. 46-50.

Neumann, Y. and Neumann, E.F. (1993), "Quality of learning experience and students' college outcome”, International Journal of Educational Management, Vol. 7 No. 1, pp. 4-10.

$\mathrm{Ng}$, I. and Forbes, J. (2008), "Education as service: the understanding of university experience through the service logic", Journal of Marketing for Higher Education, Vol. 19 No. 1, pp. 38-64.

Ning, H.K. and Downing, K. (2011), "The interrelationship between student learning experience and study behavior", Higher Education Research and Development, Vol. 30 No. 6, pp. 765-778.

Pace, C.R. (1984), "Measuring the quality of college student experiences: an account of the development and use of the college student experiences questionnaire", available at: https://eric.ed.gov/?id= ED255099 (accessed March 21, 2017).

Pass, M.W. (2013), "Quality of student effort: improving through achievement mastery and psychological needs", Atlantic Marketing Journal, Vol. 2 No. 3, pp. 43-59.

Perera, C. (2009), Operations Management: Concepts and Application, Godage International Publishers, Colombo.

Podsakoff, P.M., MacKenzie, S.B., Lee, J. and Podsakoff, N.P. (2003), "Common method biases in behavioral research: a critical review of the literature and recommended remedies", Journal of Applied Psychology, Vol. 88 No. 5, pp. 879-903.

Raj, D.M.A., Raguraman, M. and Veerappan, R. (2013), "Marketing of educational services: a new strategy for customer satisfaction", International Journal of Scientific Research and Management, Vol. 1 No. 8, pp. 435-440.

Robbins, S.P. and Judge, T.A. (2013), Organizational Behavior, Prentice-Hall, Upper Saddle River, NJ.

Roth, A.V. and Menor, L.J. (2003), "Insights into service operations management: a research agenda", Production and Operations Management, Vol. 12 No. 2, pp. 145-164.

Rumble, G. (1989), "Open learning, distance learning and the misuse of language", Open Learning: The Journal of Open, Distance and e-learning, Vol. 4 No. 2, pp. 28-36.

Sachar, M. and Neumann, Y. (2003), "Difference between traditional and distance education academic performances: a meta-analytic approach", International Review of Research in Open and Distance Learning, Vol. 4 No. 2, pp. 51-87.

Sadlo, G. and Richardson, J.T.E. (2003), "Approaches to studying and perceptions of the academic environment in students following problem based and subject based curricula", Higher Education Research and Development, Vol. 22 No. 3, pp. 253-274. 
Saunders, M., Lewis, P. and Thornhill, A. (2011), Research Methods for Business Students, Dorling Kindersley India Pvt Ltd, Noida.

Sekaran, U. and Bougie, R. (2014), Research Methods for Business: A Skill Building Approach, Wiley India Pvt Ltd, New Delhi.

Sidelinger, R.J. and Booth-Butterfiled, M. (2010), "Co-constructing student involvement: an examination of teacher confirmation and student to student connectedness in the college classroom", Communication Education, Vol. 59 No. 2, pp. 165-184.

Simonson, M., Smaldino, S., Albright, M. and Zvacek, S. (2008), Teaching and Learning at a Distance: Foundations of Distance Education, Prentice-Hall, Upper Saddle River, NJ.

Thapliyal, U. (2014), "Perceived quality dimensions in distance education: excerpts from student experience", Turkish Online Journal of Distance Education, Vol. 15 No. 3, pp. 60-67.

Tombs, A. and McColl-Kennedy, J.R. (2003), "Social-servicescapes conceptual model”, Marketing Theory, Vol. 3 No. 4, pp. 447-475.

Walter, U., Edvardsson, B. and Ostrom, A. (2010), "Drivers of customers' service experience: a study in the restaurant industry”, Managing Service Quality, Vol. 20 No. 3, pp. 236-258.

Wang, C. and Liu, Z. (2003), "Distance education: basic resources guide", Collection Building, Vol. 22 No. 3, pp. 120-130.

Wasala, R.A. (2010a), "Open and distance learning initiatives in Sri Lanka - I", The Island, August 28, p. 10.

Wasala, R.A. (2010b), "Open and distance learning initiatives in Sri Lanka - II", The Island, September 3, p. 11.

Willging, P.A. and Johnson, S.D. (2004), "Factors that influence students' decision to dropout of online courses”, Journal of Asynchronous Learning Networks, Vol. 8 No. 4, pp. 105-118.

Woolls, B., Dowlin, K. and Loertscher, D. (2002), "Distance education: changing formats", The Electronic Library, Vol. 20 No. 5, pp. 420-424.

Yuksel, A. and Yuksel, F. (2016), "Measurement of tourist satisfaction with restaurant services: a segment based approach", Journal of Vacation Marketing, Vol. 9 No. 1, pp. 52-68.

(The Appendix follows overleaf.) 
AAOUJ

12,2

170

\section{Appendix}

\begin{tabular}{llc}
\hline Dimensions & Indicators & Code \\
\hline
\end{tabular}

Construct - peripheral services (PS)

Facilitating Comprehensive training/induction on distance learning skills (as how to manage time, how FS1 services (FS) to succeed in $\mathrm{DE}$ ) was given to us

There is considerable social support for us as students (as encouragement, interpersonal FS2 communication with faculty and tutors)

Adequate administrative support (as enrollment and admission services, appeal mechanism) is available for us as students

All the relevant course information (as course objectives, assignments, timelines, study FS4 requirements, resources, learning outcomes) are provided to us on timely manner

Enhancing Psychological support (as counseling services, career guidance services) is available for us EnS1 services (EnS) as students

Financial support (as multiple and flexible payment methods, scholarships) is available for EnS2 us as students

There are alternative forms of information sharing methods (as SMS alerts, online notices, EnS3 snail mail, e-mail)

Latest technology is used in academic and non-academic activities (as online application, EnS4 registration, payments, examinations, student forums, discussion boards, access to library facilities)

There are opportunities for extra-curricular activities (as student organizations, sports) for EnS5 us as students

Construct - student experience quality (ExQ)

I am having a great time with my academic activities $\quad$ SExQ1

$\begin{array}{ll}\text { My academic activities are interesting } & \text { SExQ2 }\end{array}$

I am having a very enjoyable time with this degree program $\quad$ SExQ3

I am having a very pleasant experience with this degree program $\quad$ SExQ4

My experience with this degree program make me happy $\quad$ SExQ5

My experience with the degree program is enjoyable $\quad$ SExQ6

$\begin{array}{ll}\text { My experience is beyond words } & \text { SExQ7 }\end{array}$

I truly enjoy my experience $\quad$ SExQ8

$\begin{array}{ll}\text { I believe that I receive a superior experience at university } & \text { SExQ9 }\end{array}$

$\begin{array}{ll}\text { My experience at university is excellent } & \text { SExQ10 }\end{array}$

Construct - student involvement (SI)

$\begin{array}{lll}\text { Active } & \text { I utilize time for my academic activities regularly } & \text { AP1 }\end{array}$

$\begin{array}{lll}\text { participation } & \text { I log into LMS and get updated with study program regularly } & \text { AP2 }\end{array}$

$\begin{array}{lll}\text { (AP) } & \text { I attend day schools regularly } & \text { AP3 }\end{array}$

I actively take part in classroom discussions $\quad$ AP4

Self-learning I normally summarize what I learn in day schools and from course materials . SL1

(SF) I normally combine ideas from different courses in discussions or when completing assignments SL2

I normally connect my learning to societal problems or issues $\quad$ SL3

I examine strengths and weaknesses of my own views on topics or issues $\quad$ SL4

Student faculty I talk about my career plans with academic staff members $\quad$ Int1

interaction (Int) I discuss course topics, ideas or concepts with academic staff members outside the class Int2 I discuss my academic performance with academic staff members Int3

Table AI.

Operationalization of constructs
Learning with I ask other students to help me understand course material and subject matters peers (LP)

I normally explain course material to other students
I normally prepare for exams by discussing or working through course material with other students

\section{Corresponding author}

Hansani Chathurika Dassanayake can be contacted at: hansani@sjp.ac.lk

For instructions on how to order reprints of this article, please visit our website: 